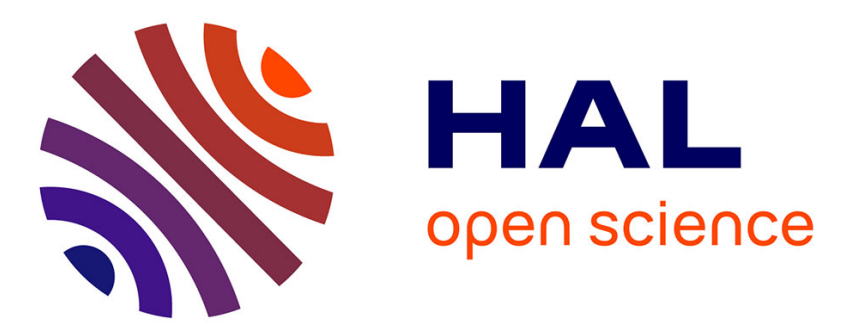

\title{
Fracture Mechanics at Intermediate Rates of Loading: The Influence of the Acceleration on Compact Tension Tests
}

\author{
P. Beguelin, C. Fond, H. Kausch
}

\section{- To cite this version:}

P. Beguelin, C. Fond, H. Kausch. Fracture Mechanics at Intermediate Rates of Loading: The Influence of the Acceleration on Compact Tension Tests. Journal de Physique IV Proceedings, 1997, 07 (C3), pp.C3-867-C3-872. 10.1051/jp4:19973146 . jpa-00255434

\section{HAL Id: jpa-00255434 https://hal.science/jpa-00255434}

Submitted on 1 Jan 1997

HAL is a multi-disciplinary open access archive for the deposit and dissemination of scientific research documents, whether they are published or not. The documents may come from teaching and research institutions in France or abroad, or from public or private research centers.
L'archive ouverte pluridisciplinaire HAL, est destinée au dépôt et à la diffusion de documents scientifiques de niveau recherche, publiés ou non, émanant des établissements d'enseignement et de recherche français ou étrangers, des laboratoires publics ou privés. 


\title{
Fracture Mechanics at Intermediate Rates of Loading: The Influence of the Acceleration on Compact Tension Tests
}

\author{
P. Beguelin, C. Fond* and H.H. Kausch \\ École Polytechnique Fédérale de Lausanne (EPFL), Laboratoire de Polymères, MX-D, 1015 Lausanne, \\ Suisse \\ *Institut Charles Sardon, 6 rue Boussingault, 67083 Strasbourg, France
}

\begin{abstract}
Compact Tension specimens were loaded at 1 and $7 \mathrm{~m} / \mathrm{s}$ with two different accelerations imposed. Experimental photoelastic patterns recorded by a high speed camera were compared with those simulated by dynamic elastic Finite Element (FE) analysis. The positive results of this comparison validated the FE analysis. It is demonstrated that when the initial acceleration of the specimen is low (using a damper in the loading device), static analysis can be applied for both testing speeds used. In high accelerations tests (without damper used), a transient dynamic stress state in the specimens is found, therefore a dynamic analysis should be used. Furthermore, in high acceleration tests a transient mixed mode of loading at the crack tip occurs.
\end{abstract}

Résumé: Deux accélérations différentes sont imposées à des éprouvettes de tension compacte (CT) sollicitées à 1 et $7 \mathrm{~m} / \mathrm{s}$. Les contraintes sont visualisée par la photoélasticité à l'aide d'une caméra à haute vitesse, et comparées avec les franges photoélastiques simulées par éléments finis. Les résultats positifs de ces comparaisons permettent de valider les calculs. Il est démontré par là que lorsque l'accélération initiale de l'échantillon est réduite par un amortisseur dans le système de chargement, J'analyse statique est applicable. Pour les accélérations élevécs, un état de contrainte dynamique transitoire est prédominent dans la phase initiale du chargement, et l'analyse dynamique doit être appliquée. De plus, dans ces tests une mixité de mode est présente en tête de fissure.

\section{INTRODUCTION}

Fracture mechanics analysis is available for various test geometries, and is based on load or displacement measurement when fracture occurs. However, the force recorded by a transducer located in the striker of an instrumented pendulum or drop weight carriage is difficult to interpret at high rates of testing because of problems in identifying the onset of fracture, particularly when the specimen is brittle. At high testing rates, inertial forces due to the rapid acceleration of the specimen interact with the external applied stress [1]. Thus, the acceleration of the tested specimen depends on the velocity of the striker, the apparent stiffness of the specimen and on the contact stiffness [2].

In the light of the above considerations, we have investigated the widespread Compact Tension geometry (CT) for the characterisation of polymers at impact rates. Several experimental measurements of the fracture toughness and studies of the associated deformation mechanisms in polymers have already been published using this technique [3]. This paper reports a more detailed mechanical approach [4].

In the experimental section, we have used the birefringence properties of CT specimens made from epoxy resin to investigate the effect of the opening velocity and acceleration by means of photoelastic analysis. Pictures of the isochromatic dynamic stress distribution were taken during the tests using a high speed camera.

Using finite element calculations to simulate a step by step dynamic elastic stress analysis, photoelastic fringes corresponding to several stages of the loading history were simulated using the same crack opening displacement versus time profile as in the experiments. These were then compared with the isochromatic fringes in the specimens recorded during the experimental loading.

\section{EXPERIMENTS}

\subsection{Testing apparatus and specimen geometry}

The specimen was loaded using a high speed servohydraulic testing machine with a piston displacement velocity of up to $10 \mathrm{~m} / \mathrm{s}$. The specimen was attached to two pins. The upper pin was stationary, connecting one side of the specimen to the frame of the testing machine, and the lower pin was mobile, being attached 
to the piston rod by a pickup unit, such that the specimen was free from load during the accelerating stage of the piston.

The force was measured at the stationary pin and special attention was payed to have a high resonumt frequency $(50 \mathrm{kHz})$ of the measuring system. An optical extensometer was used to measure precisely the opening of the moving pin.

\subsection{Photoelastic set-up}

In addition to the force and displacement measured during our experiments, the isochromatic fringes in the specimens observed in circular polarisation have been recorded using a high speed framing camera. The field of view was chosen to cover nearly the entire specimen. A Xenon flash tube was used as the light source. The flash was triggered at a certain position of the piston rod, and its duration was $1 \mathrm{~ms}$. During this time, continuous framing of the isochromatic fringes was performed using a Cordin Model 377 rotating drum camera at a rate of $5 \mu \mathrm{s}$ between frames.

Araldite B commercially available for photoelasticity measurements, and free of internal stress, was used in the present study. $V$ shape prenotches were machined into the specimens.

\subsection{Testing conditions}

It has been shown that the dynamic nature of the loading in three point bending experiments at impact rates depends on the contact stiffness between the hammer and the specimen [2]. A new testing protocol using a fracture mechanics approach at $1 \mathrm{~m} / \mathrm{s}$ is currently being investigated [5], in which it is suggested thit dynamic effects may be limited by the use a damping pad to reduce the contact stiffness between the hammer and the specimen, and hence the acceleration of the latter.

Similarly, in a high speed servohydraulic tensile tester, the opening displacement rate at a given piston speed depends on the stiffness at the surfaces of contact in the pick-up unit, the compliance of the specimen and the masses of the mechanical fixtures. The use of a viscoelastic damping material (PU elastomer) in the pick-up can decrease the acceleration of the specimen [3]. In the present study two piston speeds, 1 and 7 $\mathrm{m} / \mathrm{s}$ were used. In addition to the unmodified pick-up contact, where the materials in contact were steel ind titanium, a damping ring was used to reduce the contact stiffness.

The experimental conditions, and the corresponding designations referred to in the following sections. the time to fracture, $t_{f}$ the crack opening displacement velocity at fracture, $v_{C O D}$, and the mode 1 crack tip loading rate prior to fracture, $K_{l}$, are summarised in Table 1 :

\begin{tabular}{|c|l|c|c|c|}
\hline Experimental designation & Piston speed, damper & $\mathfrak{t}_{\mathrm{f}}(\mu \mathrm{s})$ & $\mathbf{v}_{\text {CoD }}(\mathrm{m} / \mathrm{s})$ & $K_{1}(\mathrm{GPa} \vee \mathrm{m} / \mathrm{s})$ \\
\hline $\mathbf{1} \mathbf{m D}$ & $1 \mathrm{~m} / \mathrm{s}$ with damper & 420 & 0.9 & 7 \\
\hline $\mathbf{1 m U}$ & $1 \mathrm{~m} / \mathrm{s}$ without damper & 135 & 1.7 & 17 \\
\hline $\mathbf{m} \mathbf{m D}$ & $7 \mathrm{~m} / \mathrm{s}$ with damper & $\sim 170$ & 3 & 32 \\
\hline $\mathbf{7 m U}$ & $7 \mathrm{~m} / \mathrm{s}$ without damper & $25-30$ & 9 & 65 \\
\hline
\end{tabular}

Table1: Summary of the experimental conditions

\subsection{Displacement of the moving pin}

The measured displacement of the moving pin is plotted against time in Figure 1 for the experimentu conditions in Table 1. The displacement versus time steps used in the numerical simulations are also shown.

The effect of the damping pad is clearly seen in these four experiments. In damped tests $(1 \mathrm{mD}$ and $7 \mathrm{mD}$ ), the acceleration of the specimen was nearly constant, and the opening velocity tended to that of the piston speed. In brittle materials, the fracture of the specimen may occur during the acceleration phase. before the crack opening velocity has reached the piston velocity. Nevertheless, even if the total time 10 fracture was greater for the damped test, final fracture occurred at velocities close to those of the piston. In such cases, damage mechanisms such as plasticity or localised damage, are thought to develop in the later stages of the test, where the crack tip strain rates are high.

The undamped test conditions ( $1 \mathrm{mU}$ and $7 \mathrm{mU})$, showed on the other hand, high transient acceleration. of the test components, and thus the inertial forces were important. As a result, the system was not in equilibrium and a dynamic stress state existed in the specimen. Furthermore, a loss of contact occured in the pickup between the piston and the input bar, similar to that which can occur between the hammer and tir: 
specimen in Charpy experiments. This accounts for the observation of transient opening velocities higher than those of the piston.
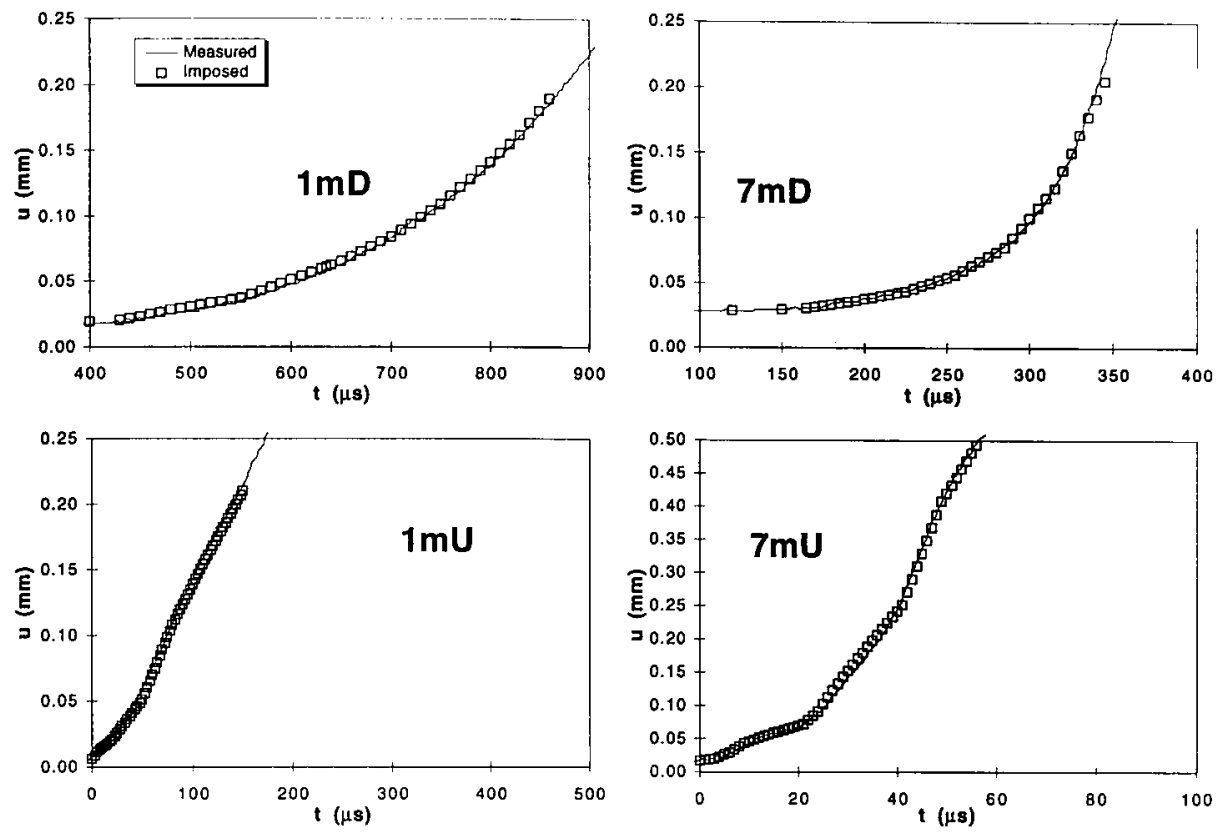

Figure 1: Displacement, $u$, versus time, $t$, for the four loading conditions studied (line: as measured by the optical device, squares: as imposed in $\mathrm{FE}$ simulation)

\section{NUMERICAL SIMULATIONS}

A dynamic stress analysis has been performed by finite element analysis (F.E.) at time intervals of $5 \mu \mathrm{s}$ using ABAQUSTM, for the loading conditions of Table 1 . The material was assumed to be isotropic and linear elastic. The analysis of the crack tip is based on the assumption of plane strain conditions, using a two-dimensional model.

The displacement conditions were imposed on three neighbouring nodes on both sides of the structure.

The isochromatic pattern was generated by software developed in house, using nodal displacements from the finite element calculations. These were interpolated with the isoparametric functions of the four node elements to deduce strains and stresses. The number of fringes is proportional to the shear stresses:

$$
\sqrt{I}=\cos \left(\pi\left(\sigma_{1}-\sigma_{2}\right) B / C\right)
$$

where $I$ is the light intensity, $\sigma_{l}$ and $\sigma_{2}$ are the principal stresses, $B$ is the thickness of the specimen and $C$ is the photoelastic constant.

\section{RESULTS}

The experimental and the simulated isochromatic patterns were compared over the total duration of the test for each set of loading conditions. It is reasonable to assume that a good spatial and temporal correlation of the shape and the order of the fringes will validate the F.E. calculations.

\subsection{Comparison between the experimental and simulated photoelastic patterns}

The comparison between the experimental and simulated photoelastic patterns was done for time steps of 5 $\mu \mathrm{s}$ which was the time interval between the frames taken by the high-speed camera. As an example, a 
selection of true and simulated fringes patterns for the two loading conditions at $7 \mathrm{~m} / \mathrm{s}$ is discussed in whal follows. The similarity of the experimental and the simulated patterns was satisfactory, given a tolerance of half an order in the isochromatic fringes.

$7 \mathrm{mD}$ : For relatively high nominal testing velocity of $7 \mathrm{~m} / \mathrm{s}$, the stress state was found to be somewhit asymmetric in the specimen, as shown in Figure 2. Nevenholess, as will be seen in the next section, owing to the reduced acceleration, such a stress state could be assimilated to a quasi-static one. In comparison with the loading condition $1 \mathrm{mU}$, the total time to fracture was extended. Rapid crack propagation occurred in it similar manner to that of the $\mathrm{m}$ U U test. The first few millimetres of the crack propagation occured in thi mid-plane. Then, owing to the additional stress supplied by the input bar during the crack propagation, the crack deviated toward the moving pin.

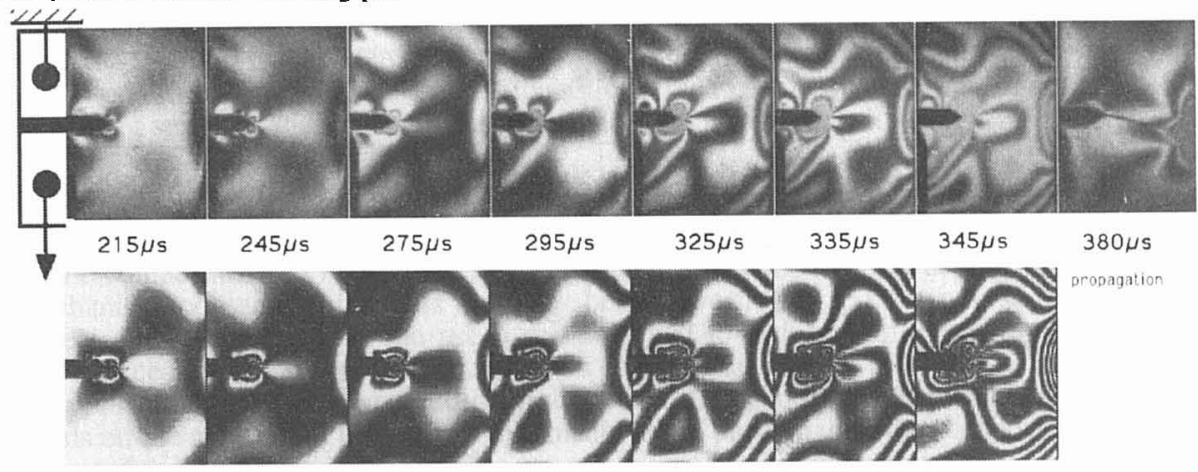

Figure 2: Experimental (above) and simulated (helow) photoelastic fringes at a nominal opening velocity of $7 \mathrm{~m} / \mathrm{s}$, where the acceleration was reduced by the use of a damper $(7 \mathrm{mD})$

$7 \mathbf{m U}$ : This was a rather severe testing condition. The test was extremely short $(<30 \mu \mathrm{s})$. As show'n in Figure 3, a fully dynamic (time dependent) stress distribution existed in the specimen. It was highly asymmetric, and essentially the stress waves had not reached the stationary pin (the upper one in the ligure) when the fracture occured. The fringes surrounding the crack tip reflected a complex local stress distribution. The crack propagation started at an angle, moving towards the more highly stressed regions if the specimen

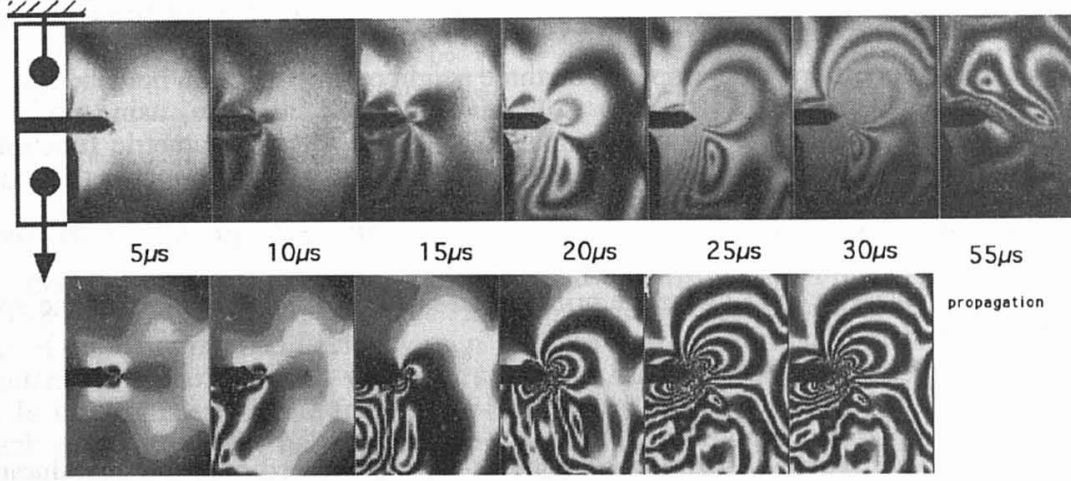

Figure 3: Experimental (above) and simulated (below) photoelastic fringes at a nominal opening velocity of $7 \mathrm{~m} / \mathrm{s}$. where the test was undamped $(7 \mathrm{mU})$.

According to these photoelastic patterns, the use of a reduced acceleration extended the lifetinc of the specimen. The total time to fracture was much ionger when a damper was used than in an undamped lest. 
but even if the effect of the loading history depended on the material itself, the increase in time to fracture occured mainly in the early stages of the test, when the stress in the specimen was the lowest.

\subsection{Comparison between the experimental and simulated LEFM parameters}

Since the computational F.E. procedure was considered as being validated by the above comparison between the experimental and the dynamically simulated isochromatic patterns, we could compare the experimental measurements with the results of the F.E. calculations.

In the application of our experimental procedure with the acceleration reduced by the damper, the Stress Intensity Factor (S.I.F.) were estimated from the load signal, applying the static analysis:

$$
K_{l}=f \frac{F}{B W^{1 / 2}}
$$

were $f$ is a geometrical factor, $F$ is the force, and $W$ and $B$ are the dimensions of the specimen.

Figure 4 shows plots of the S.I.F. in mode I (cleavage mode) calculated from the force measured by the load-cell, in comparison with the S.I.F. at the crack tip determined by F.E. analysis. The S.I.F. in mode II (shear mode) was also available from the F.E. analysis. The absolute value of the mode mixity ratio, $\left|K_{l} / K_{l}\right|$, has been plotted in the graphs. For the $7 \mathrm{mU}$ condition, although the time at which the fracture occurred is shown on the graph, the S.I.F. calculated from the measured force has not been plotted, since as we have seen, this is meaningless.
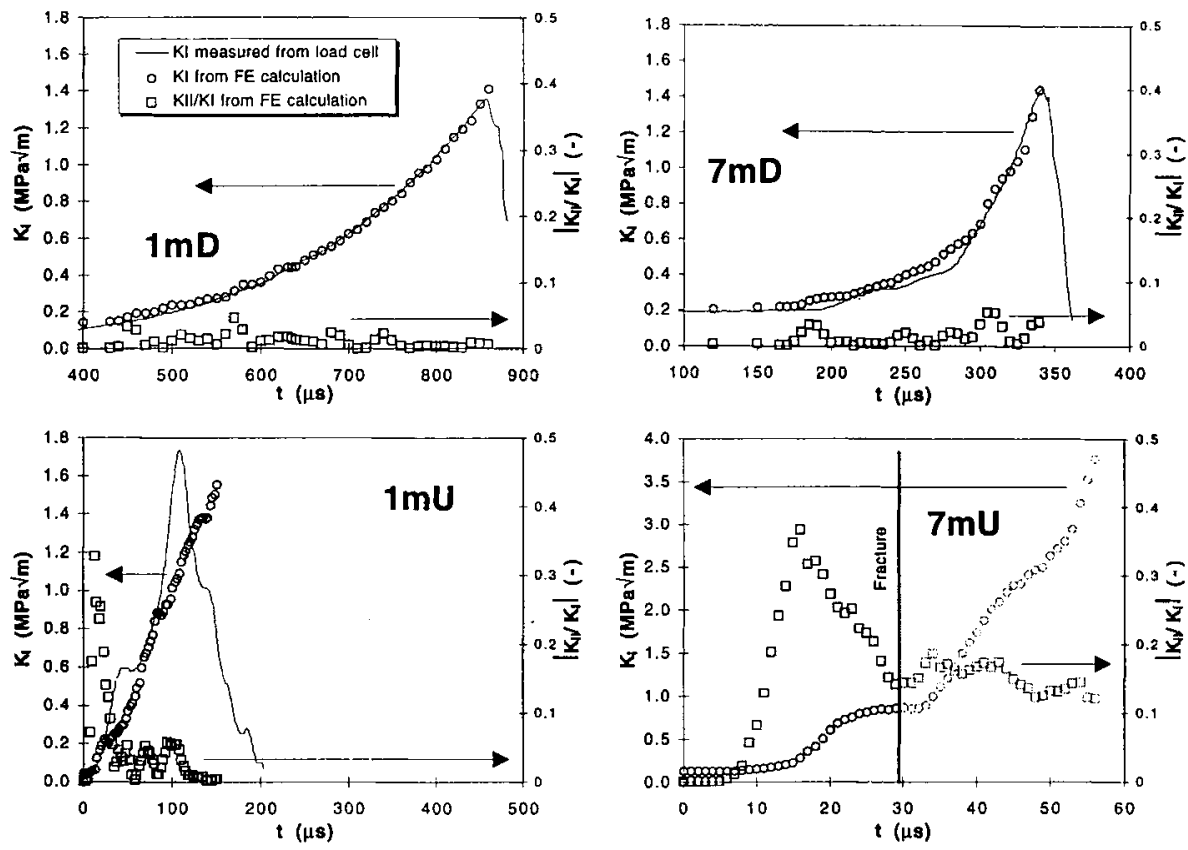

Figure 4: Comparison between the measured and calculated Stress Intensity Factors, $\mathrm{K}_{\mathrm{I}}$, versus time, $\mathrm{t}$, for the four loading conditions studied. The experimental S.I.F. in mode I were calculated from the force measured by the load cell; the ratio of the S.I.F. in mode $I$, and in mode $\Pi,\left|\mathrm{K}_{11} / \mathrm{K}_{1}\right|$ calculated by F.E. are shown.

For both damped loading conditions, $1 \mathrm{mD}$ and $7 \mathrm{mD}$, the $K$, calculated by F.E. from equation (2) were in good accordance with the $K_{l}$ calculated from F.E. analysis. One can conclude, therefore, that the measure of the forces acting on the stationary pin was representative of the external forces applied to the specimen. A static fracture mechanics analysis based on such a measurement may thus be performed. When the same comparison was made at $1 \mathrm{~m} / \mathrm{s}$, without the damper $(1 \mathrm{mU})$, the result showed a rather poor correlation. The calculated and measured oscillations of the S.I.F. were out of phase, and moreover those of the measured 
$K_{l}$, resulting from the resonance of the system were higher than those estimated from the calculation. Finally, the identification of the moment of specimen fracture in a such case is difficult, because of these oscillations.

\section{DISCUSSION}

The asymmetrical stress-state in the specimen observed in some photoelastic patterns resulted from the transient dynamic nature of the loading. The effect of the distorted stress field was to induce some Mode II at the crack tip. Although the ratio of mode mixity, $\left|K_{I f} / K_{l}\right|$ remained low in the damped loading conditions, as can be seen in the top of Figure 4, the stress-state of the specimen became slightly assymetric at $7 \mathrm{~m} / \mathrm{s}$ (Figure 2). Since in our testing configuration, the specimen was loaded by the motion of the lower pin only. $10 \mathrm{~m} / \mathrm{s}$ should be considered as being the upper limit of such a damped test. At higher speeds, Mode II mals: become higher and mixed mode fracture could occur. During the early stages of the undamped loading the mode mixity, $\left|K_{l} / K_{l}\right|$ was significant (bottom of Figure 4). In this latter case, if the fracture had occured after short loading time, the crack propagation would have started towards the moving part of the specimen (the lower part), as can be seen in Figure 3.

In the damped tests $(1 \mathrm{mD}$ and $7 \mathrm{mD}$ ) the total time to fracture was obviously greater than in the undamped tests. However, the final fracture occured at high velocity, close to that of the piston. The velocity at the moving pin, $\dot{u}$, and the crack tip loading rate, $K_{i}$, have been assessed by the calculation of the numerical derivative of $u$ used for the F.E. simulation, and the resulting $K_{l}$ values. For the undamped loading conditions, $K_{t}$ was higher than for the damped loading conditions, but ultimate values of $k_{l}$ obtained at fracture initiation were of the same order of magnitude, as shown in Table 1. The most remarkable distinction between the different testing conditions was the oscillating nature of $K_{I}$, resulting from the undamped loading, which contrasted with the almost constantly increasing $K$, in the damped cests. It is difficult to estimate the effect of such differences in the loading history of the specimen on the critical S.I.F. measured, because they depend on the tested material itself.

The undamped loading conditions should thus be considered to be rather more severe testing conditions than the damped ones. However, as well as the much greater experimental ease with which one can oblain reliable S.I.F. from the damped tests, these latter yield a better characterized and less complex stress statc in the specimen.

\section{CONCLUSIONS}

The combined use of experimental and computational techniques has contributed to a better understanding of the effect of the acceleration taking place in rapidly loaded CT specimens. When the opening of the specimen is achieved by the displacement of one pin only, the other being fixed, inertia effects resuling from the high acceleration can lead to a dynamic asymmetrical stress state in the specimen. For materials showing short times to fracture (brittle materials) this can induce mixed mode fracture in the specimen.

Both experimentation and computation, showed that a high test speed of $1 \mathrm{~m} / \mathrm{s}$ without damping should be considered as the upper limit of such mode I tests. Indeed, even in this case the S.I.F. could not be accurately deduced from the imposed displacement and from the measured force. Furthermore, the stress state in the specimen was highly influenced by the dynamic nature of the loading. Therefore, in the experimental determination of the S.I.F., the use of a damper in order to limit the acceleration of the moring pin was preferred. Such a setup lead to less severe, but better defined testing conditions. By reducing the acceleration of the test, it was changed from a dynamic transient impact test to a high loading rate quasistatic fracture test, the strain rate being of the same order of magnitude.

Furthermore, this study has shown that comparable high speed fracture tests can lead to very different stress states in the specimen depending on the acceleration of the specimen involved in the test.

\section{References}

[1] Böhme W., Kalthoff J.F., Journal de Physique, Colloque C5, 46 (1985), C5-213-218

[2]Williams J.G., Fracture mechanics of Polymers, Ellis Horwood Limited (1987)

[3] Béguelin Ph, Kausch H.H., Journal of Materials Science 29, (1994), pp.91-98

[4] Béguelin Ph., Fond C., Kausch H.H., The Influence of the Inertial Effects on the Fracture Mode of Rapidly Loaded Compact Tension Specimens, submitted to Int. Journal of Fracture

[5] ESIS, Technical Commitee4 